\title{
NOVI PRISTUP POETSKO-LIKOVNOM OPUSU VLADE PULJIĆA
}

\author{
Barbara MARTINOVIĆ \\ Filozofski fakultet \\ Matice hrvatske b.b. \\ $\mathrm{BiH}$ - 88000 Mostar \\ E-pošta: barbara.martinovic.bm@gmail.com
}

UDK 821.163.42(497.6)-1.09 Puljić $V$.
75.071 Puljić $V$.
Stručni rad
Primljeno: 24. travnja 2015.
Prihvaćeno: 16. lipnja 2015.

Sažetak

U radu se govori o novom pristupu stvaralaštvu umjetnika Vlade Puljića kroz odabrane primjere njegove poezije i slikarstva. Kao teorijska podloga interpretaciji odabran je semiotički pristup. Rad je podijeljen na dva dijela, od toga je jedan teorijski uvid u razliku slike i riječi, dok drugi kroz konkretne primjere Puljićeva opusa razmatra znakove koji su temelj njegova stvaralaštva.

Ključne riječci: Vlado Puljić, slika i riječ, semiotika, znak, Hercegovina. 


\section{Odnos djela i kritike}

O stvaralaštvu Vlade Puljića mnogi su pisali kritike, oglede i komentare. Većina tih komentara spominje činjenicu da je Puljić bio pjesnik i slikar, međutim njegovom stvaralaštvu pristupaju gotovo u pravilu odvajajući riječ i sliku. $\mathrm{Na}$ žalost, danas je Vlado Puljić gotovo zaboravljen, možda zahvaljujući upravo kritici koja mu nije ozbiljno pristupila. Istina, mnoge su njegove slike ispunile hercegovačke domove, njegove se anegdote prepričavaju po kavanama, međutim pravoga kritičkog pristupa i valoriziranja njegova stvaralaštva nema. Kada govorimo o kritici, moramo spomenuti da većina autora piše o Puljiću u određenoj vrsti slobodne forme, te da je to više komentar na njegovo stvaralaštvo nego umjetnička kritika. U većini slučajeva ta je kritika površno napisana, bez iščitavanja njegovih pjesama i analize njegovih slika, te je kao takva utjecala na opće shvaćanje Vlade Puljića kao slikara. Ako ćemo se voditi za jednostavnim objašnjenjem odnosa djela i kritike, onda bi to bilo da se kritika odnosi prema djelu kao određena rekonstrukcija i/ ili interpretacija. Imajući to na umu, onda znamo kakva je interpretacija Puljićevih djela nastala kroz površne komentare. Iznijet ćemo neke od tih komentara/kritika, te analizirati navedeno u svrhu boljega razumijevanja pročitanoga. Tako pri otvaranju izložbe u Sarajevu 1996., Mirko Marjanović iznosi sljedeće.

"...on je iznad svega pjesnički, rođen u lirskoj duši koja realni svijet juga dodiruje riječju, a onda crtežom i bojom. Onaj tko Puljića kao umjetnika bolje poznaje, tko, dakle ne odvaja strogo jezik njegove poezije od jezika njegovog likovnog stvaralaštva... Najsažetije kazano, Puljić je slikar kakav je i pjesnik, a pjesnik kakav je i slikar."1

Osim što je navedeno u suprotnosti jer prvo navodi da je Puljić iznad svega pjesnik, a tek onda slikar, govori također da je Puljić jednako snažan kao pjesnik i kao slikar. Ako ćemo prijeći preko toga "natjecanja" je li on bolji pjesnik ili slikar, autor nam ne daje nikakve dublje analize činjenice da Puljić ne odvaja jezik poezije i jezik likovnoga stvaralaštva, također ne daje nikakav primjer toga (ne)odvajanja.

Alija Kebo, pjesnik i novinar barem potkrjepljuje rečeno o spajanju riječi i slike rečenicama samoga umjetnika.

"Primjećujemo: njegove slike kao da dopunjuju pjesmu, i, obratno, kao da je svaki stih izvučen nekom tankom linijom koja ode od svakodnevnih običnih doživljaja do onih što znače umjetnikove životne spoznaje i drame. Otuda i Puljićevo objašnjenje - obje ove ljubavi meni donose iste nemire i pobuđuju istu radoznalost. Ono što ne mogu da dosegnem zvukom boje, to nadoknađujem životvornom moći stiha." ${ }^{2}$

Ono što se nastavlja dalje u svim tim ogledima/komentarima, jest divljenje Puljiću zbog njegova dva talenta, čime se dobiva dojam da mu se treba diviti samo zbog toga. Njegovo stvaralaštvo ostaje neinterpretirano, neistraženo i nedovoljno valorizirano upravo zbog

1 Vlado Puljić: likovno-poetska monografija, Matica hrvatska, Mostar, 2000., str. 24.

2 Usp. Isto, str. 22. 
toga jer većina onih koji su pisali o njemu više su se trudili dokazati je li on bolji pjesnik ili slikar bez ikakve podloge u smislu analize i iščitavanja.

Jedan od onih koji se izdvajaju pozitivno (osim nekih književnih kritika koje su ipak malo temeljitije pristupile njegovoj poeziji) jest Vojislav Vujanović koji pristupa savjesno i analitično Puljićevu stvaralaštvu, te usmjerava na to da Puljićevo likovno djelo ne proistječe iz pjesničkoga, nego da nastaju paralelno, te da to nije nekakav imaginarni hijerarhijski odnos, nego posljedica unutarnjega rada njegova pjesničkog i likovnog agona. ${ }^{3}$

U želji za pravilnom valorizacijom, time i mogućom interpretacijom $\mathrm{Pu}$ liićeva stvaralaštva, analizirat ćemo njegovo djelo kroz riječ i sliku, odnosno kroz poeziju i slikarstvo. Pri tome će se prvo postaviti kvalitetna teorijska, odnosno semiotička podloga koja će biti počelo same interpretacije.

\section{Riječ i slika}

Prije nego pristupimo mogućoj interpretaciji i analizi Puljićeva djela, moramo razmotriti odnos riječi i slike. Kao što su gore navedeni autori naglašavali, Vlado Puljić je bio pjesnik i slikar. Čak i njegova jedina monografija koju je sam koncipirao, nazvana je likovno-poetska monografija, iz čega zaključujemo da sam Puljić nije želio odvajati svoje umjetničke darove. Čitajući monografiju, koja je kako on navodi nastala spontano, vidimo da uza svaku svoju sliku postavlja pjesmu. Taj autorski nagon daje nam za pravo da postavimo kao imperativ razmatrati njegovo stvaralaštvo kroz poeziju i slike istodobno, ne odvajajući ih. U raspravu razlika slike i riječi ne ćemo ulaziti odveć detaljno, međutim moramo u suglasju $s$ najpoznatijim polemičarom te tematike navesti nekoliko značajki.

W. J. T. Mitchell navodi kako zamišljamo da je rasjed između riječi i slike širok koliko i onaj između riječi i stvari, između prirode i kulture. On pretpostavlja da bi Derridin odgovor na pitanje "Što je slika?" nedvojbeno bio: "Ništa drugo nego nova vrsta pisanja, vrsta grafičkoga znaka koji se prikriva kao izravan transkript onoga što prikazuje, ili onoga kako stvari izgledaju ili što su u svojoj biti. ${ }^{4}$ Upravo zbog toga rasjeda riječi i slike kako on navodi, Puljićevo je djelo ostalo nedovoljno promatrano i iščitano, jer se većina autora nakon što navede činjenicu da je slikar i pjesnik, zadrži na poistovjećenju riječi ili slike, zanemarujući ozbiljnije analizirati jedan ili drugi dio njegova stvaralaštva. Derridin pretpostavljeni odgovor na pitanje što je slika (u odnosu na riječ) vodi nas upravo do semiotike kao moguće prave teorijske podloge za ovakvo iščitavanje cjelokupnoga Puljićeva umjetničkog stvaralaštva. Ako je slika ništa drugo nego samo nova vrsta pisanja, vrsta grafičkoga znaka, onda ćemo na taj način i pristupiti umjetniku, jer on kroz dvije vrste pisanja (riječ i slika) stvara svoje umjetničko djelo.

3 Usp. Isto, str. 5.

4 Usp. William John Thomas Mitchell, Ikonologija, slika, tekst, ideologija, Zagreb, Antibarbarus, 2009., str. 39-51. 
U svrhu još boljega pojašnjenja rasjeda između slike i riječi, poslužit ćemo se mislima nekih od teoretičara koji su se bavili tim područjima umjetnosti.

"Nejezični sustavi se razlikuju od jezika, slikanje od opisivanja, reprezentacijsko od verbalnoga, slika od pjesme, prvenstveno po nedostatku razlučivosti - zapravo po gustoći simboličkoga sustava... neki je sustav reprezentacijski samo ukoliko je gust... značajna razlika leži u međuodnosu simbola u denotativnom sustavu."5 Filozof Goodman ovim zaključuje razliku između slike i riječi kojima se bavi u svojoj teoriji simbola. Simbolički sustav slike gušći je od simboličkoga sloga riječi upravo zbog toga jer npr. jedan potez kista plave boje sadrži u sebi puno više simbolike, nego recimo napisano slovo ili riječ. Slovo A će, npr., kako god da ga napišemo imati uvijek isto značenje, bez obzira na korišteni sustav, dok će potez plave boje, ovisno o ostalim elementima na slici, biti simbolički gušće nabijen.

$S$ druge strane, vrijedno je spomenuti Lessinga koji upozorava na ograničenost medija kojim se koriste poezija i slikarstvo. On govori o tome da je slikarstvo prostorna, a poezija vremenska umjetnost. Poezija ima širu sferu zbog beskrajnoga dosega naše mašte i neopipljivosti njezinih slika, dok je slikarstvo prostorno ograničeno. On također postavlja i tabelu oprječnosti slike i riječi, pa tako navodi da slikarstvu pripadaju prostor, prirodni znakovi, ograničeno područje, tijelo, ljepota i oko, a poeziji pripada vrijeme, arbitrarni znakovi, beskrajan prostor, um, uzvišenost i uho. ${ }^{6}$

Da ne bismo, pak, previše ušli u raspravu o razlikama između slike i riječi, naveli smo samo neke od tih rasjeda koji ih dijele - kroz odabrana slikana djela i napisane stihove Vlade Puljića pokušat će se dati uvid u simboličko znakovlje njegove slike i riječi.

\section{Puljićevo znakovlje ${ }^{7}$}

Za analizu stvaralaštva koje obuhvaća poeziju i slikarstvo, potrebno je pronaći pristup pomoću kojega je moguće oboje interpretirati bez stavljanja jednoga ispred drugoga. Takvo što zahtijeva odmicanje od tradicionalnoga odvajanja (time i interpretiranja) riječi i slike. Međutim, razumijevanje specifičnosti slikovnoga sloga u odnosu na jezično izražavanje otežano je činjenicom da prvo u sebi nosi "talog neizrecivog" i "govor šutnje", a drugo posjeduje svoju neuhvatljivu slikovnu dimenziju - slikovni aspekt jezika sukonstituira značenje od doslovnoga do metaforičkoga. ${ }^{8}$

Kako je semiotika fundamentalno transdisciplinarna teorija ${ }^{9}$ koja se

5 Nelson Goodman, Jezici umjetnosti (Pristup teoriji simbola), Kruzak, Zagreb, 2002., str. 9-31.

6 Usp. W. J. T. Mitchell, nav. dj., str. 108-117.

7 Ukupnost znakova koji se odnose na neki zajednički problem, u ovom slučaju Puljićevo stvaralaštvo.

8 Usp. http://www.zarez.hr/clanci/hermeneutika-ikonickog-i-verbalnog-znaka, SoNJA BRISKI UZELAC, Hermeneutika ikoničkog i verbalnog znaka (1. 4. 2015.).

9 Usp. Mieke Bal - Norman Bryson, "Semiotics and Art History", u: The Art Bulletin, Vol. 73, br. 2, 1991., str. 175. 
može primjenjivati i u književnim i u likovnim analizama, čini se da je ona prava teorijska podloga za proučavanje Puljićevih umjetničkih poruka. No, da bismo bliže prišli njegovu znakovlju, moramo razjasniti pojmove koji su nužni za daljnje razumijevanje zahvaćenoga.

Pojmove koji se tiču semiotičke analize razmotrit ćemo kroz teorijske osnove slovenskoga semiotičara Brace Rotara i američkoga filozofa Charlesa S. Peircea. Oni se obojica oslanjaju na Saussurea, a ono što ih posebno povezuje jest činjenica da su obojica razmatrali semiotiku u okvirima likovne umjetnosti.

Peirce definira znak u širem smislu kroz trijadični odnos: "(...) Znak, ili reprezentamen, nešto je što po nekome svojstvu ili osobini stoji umjesto nečeg drugog. On se nekome obraća, to jeste u umu dotične osobe stvara istovrijedni znak ili, možda, razrađeniji znak. Tako stvoren znak nazivljem interpretantom prvog znaka. Znak stoji umjesto nečega, svojeg predmeta. On stoji umjesto toga predmeta ne u svakom pogledu nego kao referencija na neku vrstu ideje koju sam katkad nazivao temeljem reprezentamena." ${ }^{10}$

Dakle, postoji znak koji predstavlja nešto drugo i postaje predmet koji jest ono umjesto čega stoji znak i značenje, odnosno interpretant.

Braco Rotar kroz pojam likovne govornice razrađuje tezu semiotičkog pristupa slikarstvu. Pri tome navodi da su osnovni elementi toga znakovi i boje. Za razliku od Peircea, on pronalazi čiste i aluzivne znakove. Pri tome je aluzivni znak puno općenitiji od ikoničkoga znaka, dok je boja primarna semiotička jedinica. Rotar zaključuje da se interpretacija djela uspostavlja opažanjem zakonitosti, tj. likovnoga koda koji kao slika proizlazi iz pogleda umjetnika na svijet. ${ }^{11}$

Nadalje, vrijedno je zabilježiti i to da semiotika likovne elemente tretira kao znakove (ikoničke, aluzivne, indeksne itd.) i pokušava u njihovim znakovnim odnosima otkriti posebna i specifična pravila označavanja koja vrijede za pojedinačno djelo, stil, školu i sl. ${ }^{12}$

Uzevši sve ovo u obzir, moguće je specifična pravila označavanja promatrati kao fenomen koji vrijedi samo za jednoga umjetnika - u ovom slučaju Vlade Puljića.

Zato ćemo izdvojiti neke bitne znakove iz njegova stvaralaštva, neovisno o tome pripadaju li oni poeziji ili slikarstvu, te ih interpretirati u kontekstu njegova pjesničkoga i slikarskoga stvaralaštva. Pri tome ne ćemo obuhvatiti njegovo cjelokupno likovno-poetsko stvaralaštvo, nego samo zbirku poezije Veliki čempres i neka reprezentativna djela slikarstva reproducirana u njegovoj monografiji.

Pristup Puljićevu stvaralaštvu, kao kompatibilnom sustavu znakova, odabran je upravo zbog nemogućnosti odvajanja i posebnoga interpreti-

10 Jorgen Dines Johansen - Svend Erik Larsen, Uvod u semiotiku, Croatialiber, Zagreb, 2000., str. 45.

11 Usp. Miš́o Šuvaković, Pojmovnik suvremene umjetnosti, Horetzky, Zagreb, 2005., str. 346-347.

12 Isto, str. 348. 
ranja njegovih književnih i likovnih ostvarenja. I ovdje odmah treba napomenuti: poetsko-likovni prostor Puljić ispunjava znakovima koji svojim značenjem prizivaju pitanja ljudske egzistencije, odnosno čovjekova bitka uvjetovanog teškim materijalnim (i ne samo materijalnim) okvirima življenja. Tu se možemo referirati na M. Heideggera koji razlaže pojmove bitka, tubitka i egzistencije. Spasiti neku stvar, prema Heideggerovom mišljenju, znači prije svega unijeti je u njezinu bit da bi je ta bit dovela do istinskoga sjaja. ${ }^{13}$

Prvi od presudnih znakova/simbola koje pronalazimo u Puljićevoj poeziji jest sunce. Sunce je u Puljićevim stihovima (ne)prijatelj, uzrok rana i žeđi, ali isto tako i prijatelj zmijama i guštericama. Međutim, kada govorimo o Puljićevu slikarstvu, iako Puljić slika i sunce i svjetlost, pogrješno je zaključiti da je on slikar svjetlosti (kako su navodili neki od prijašnjih kritičara). Slikari svjetlosti (o kojoj je toliko pisano kada je riječ o Mostaru) jesu Karlo Afan de Rivera i Antun Motika. Njihovi su akvareli prozračni, lagani, puni tople svjetlosti i svijetlih boja. Nasuprot tome, Puljićeve su slike zagasitih boja i krutih oblika.

U zbirci pjesama Veliki čempres već druga pjesma nosi naziv Sunce, te na određeni način predstavlja početak označavanja Sunca (što će se kasnije kroz druge pjesme ponešto i promijeniti).
"Sjedim na vrhu brijega/ poput srušena zvonika./ Okolo nema nikoga,/ iznad mene ničega:/ ni ptice,/ ni neba,/ ni boga,/ samo sunce, sunce.// Ose sunca sasule žalce:/ u trsovima,/ u suhoj travi,/ u cvrčku na kamenu/ kao na tavi/ cvrči sunce."14

Ova je pjesma gotovo kao uvod u cijelu zbirku, a možemo je zamisliti kao početni kadar filma. Urušeni zvonik metafora je za srušenu vjeru ali i za odlazak i nestajanje ljudi: uokolo nema nikoga; ni iznad pjesnika, gore, nema ničega $\mathrm{i}$ on nabraja čega to nema; nema ptica koje su poveznica neba i zemlje, nema ni neba kao onog što je iznad zemlje pa to automatski povlači i misao da nema ni Boga koji već po konvencionalnim razmišljanjima pripada nebu. U drugoj pjesničkoj slici zrake sunca Puljić uspoređuje s osinjim žalcima koji su svugdje oko nas, a stih završava slikom sunca koje cvrči kao na tavi.

U pjesmi U hladu smokve, sunce izgoni lirskog subjekta i oko njega šište zmije sunca. Sunčana nepogoda u pjesmi Bog ljeta nadovezuje se na pjesmu Neretva, u kojoj je rijeka okupila narod s obje strane da u njoj liječi sunčane rane. Dakle, Puljićevo je Sunce znak koji funkcionira neovisno od znaka Boga, neba i zemlje. Ono je tu i upravlja životima, ono je nepogoda, ono uzrokuje rane, izgoni ljude. To nije svjetlost kakvu u svoje slike unose De Rivera i Motika, ili svjetlost kakvu Andrić opisuje u djelu

13 Usp. Saša Radovanović, "Suština tehnike i mogućnost umetnosti kao onog-spasonosnog u Hajdegerovom mišljenju", u: Filozofija i društvo, Institut za filozofiju i društvenu teoriju, br. 1, Beograd, 2009., str. 103.

14 Vlado Puljıć, Veliki čempres, Udruženje književnika Bosne i Hercegovine, Mostar, 1986., str. 8. 
Znakovi pored puta. To su osinji žalci koji cvrče, bodu, prijete i neovisno o svemu drugome, upravljaju životom.

Drugi presudni znak/simbol u Puljićevu stvaralaštvu jest kamen koji se kao znak ističe i u njegovim poetskim i u njegovim likovnim ostvarenjima. $\mathrm{Na}$ određeni način kamen i sunce jesu ravnoteža između koje se događa život koji oboje uvjetuju.

U Puljićevu likovnom opusu figurira djelo "Ljuti krš" iz 1961. godine, koje bi moglo stajati kao slika - znak iz koje niču svi ostali likovno-poetski poticaji. U prvom planu koji zauzima veći dio slike prikazana je suha zemlja ispresijecana kršom. U trećem se planu nazire nebo bez oblaka. Sve je u savršenoj ispucaloj horizontali, osim na lijevoj strani slike gdje se jedva zamjetno nalazi usahlo slomljeno drvo. Boje zemljane i zagasite još više pridodaju tmurnoj atmosferi slike. Niti jedan oblik nije jasno naglašen. Da nema drveta koje prkosi horizontali slike, djelo bismo svrstali gotovo u apstraktno rješenje. Upravo zbog nenaglašenih oblika, ovo ćemo djelo uzeti za početak/ishodište ostalih likovnih znakova. Svaki Puljićev likovni i/ili poetski znak izrasta iz ovog suhog i tmurnog krajolika, iz motiva Hercegovine koja, ako pratimo znakove, izrasta i živi između kamena i sunca.

U svim Puljićevim umjetničkim ostvarenjima kamen je veoma zanimljiv i često korišten znak.

"Kamen krije zmiju/ iako zlo joj misli// Mada zlo joj misli neće da je oda.// Već čeka trenutak/ da sazrije sunce-/ kad zmiju opije sloboda;/ tad nabasa ruka ljudska,/ podigne kamen/ i glavu joj smrska."15

Naziv ove pjesme je Naličje kamena, a u njezinim stihovima opisana je druga, skrivena strana kamena. Cijela pjesma ima gotovo zastrašujuću atmosferu, što se osobito potvrđuje odabirom riječi u zadnjem stihu.

Veoma je zanimljiv način na koji $\mathrm{Pu}-$ ljić sa samo desetak znakova, koje kroz cijelu zbirku ali svaki put na potpuno drugi način ponavlja, uspijeva proniknuti u bit egzistencijalnih problema zavičajne sredine.

Tako u pjesmi Bog je kamen u mom kraju kamen na kraju postaje Bog.

"A gospe sasušene kao vrbe/ s izjecalim grudima i očenašima/ u slomljenim krunama grijehe kaju./ Bog ne čuje njihove molitve među brdima-/ Bog je kamen u mom kraju."16

Nesumnjivo misleći na svoj hercegovački kraj Puljiću je kamen jednako stvaran i važan kao i sunce: kamen skriva zmiju, na kamenu se gušterica sunča, kamen je oružje, kamen je život, kamen je onaj koji šuti, onaj koji je postojan, kamen je sveodređujući, kamen je Bog.

I znak žedi svakako je jedan od presudnih a možda i najizražajnijih poetskih znakova u Puljićevu umjetničkom opusu. I bez čitanja njegovih pjesama, znak žeđi dovoljno je izražajan, međutim prožet poetskim srhom on postaje sasvim nešto drugo - postaje znak nemoći i nemogućnosti promjene. Žeđ je produkt (ne) 
ravnoteže kamena i sunca. Puljić to sjajno navodi u pjesmi Žed: "Žed pradjedovsku naslijedih od oblaka."17

Ovdje se, naravno, odmah moramo referirati i na pjesmu Oblaci, jer i oblaci su jedan od presudnih znakova/simbola podneblja:

"Oblaci-sijači polja/ imaju dušu kruha./ Pohrlimo im u susret/ onesviješćena zemljo!"18 Oblaci koje "prizivamo u mislima-/ i gušterica na kamenu opsjednuta suncem." ${ }^{19}$

No oblaci su znak nade, što je suprotno od onoga uobičajenog označavanja oblaka i sunca.

$\mathrm{Na}$ znak oblaka nadovezuje se znak kišs koja... "slavljena usnama ispucalim/ kao svetinja/ kiša u brazdama/ žarom kruha tinja." 20

Dok su oblaci znak nade, kiša je znak života i slavi se kao svetinja.

Kao što se može primijetiti, u Puljićevu poetskom svijetu sve je diktirano i (pred)određeno prirodnim pojavama.

Uza znakove žedi i kiše vežemo možda najizražajnije Puljićevo djelo, sliku Žena s ljèsom iz 1966. godine. U središnjem dijelu slike prikaz je žene. Međutim, dominanta slike, naglašena upravo veličinom i postavljanjem u prvi plan, jest ljèsa na kojoj se suše raspoređeni plodovi prirode (smokve). Žena svojom nošnjom i ljèsa odaju ambijentalne značajke hercegovačkoga područja, iako to samim prostorom nije naznačeno. Međutim, poznajući Puljićev poetski prostor, znamo da je i ovdje riječ o istom (zavičajnom) prostoru.

Nakon pročitanih pjesama, Puljićeve slike dobivaju potpuno drugu dimenziju iščitavanja. Naime, kada ženina nošnja i ne bi bila karakteristična za određeni prostor, kada bismo vidjeli samo prostor u kojem je naslikana, opet bi taj prostor lako povezali s $\mathrm{Pu}$ ljićevim poetskim prostorom. Po boji, određenoj praznoći, polusuhom drveću i licu žene prepoznajemo prostor. Promatrajući sliku, gotovo primjećujemo da stihovi o ženama sasušenim kao vrbama, ženama ispucalih usana koje dozivaju kišu, dobivaju svoj oblik karakterističan za prostor kojeg Puljić misli i duboko doživljava.

Žena čije je lice subdominanta slike, lice koje je jedva naglašeno s minimalno malim brojem poteza, najsnažniji je detalj na slici. Puljić je sa samo nekoliko poteza uspješno prikazao izmučeno lice iz svojih pjesama. $S$ ovim licem možemo povezati bezbroj poetskih znakova - slika dobiva na svojoj punoj vrijednosti tek nakon iščitanih pjesama.

Osim na lice, pogled se gledatelja usmjerava i na ruku koja je namjerno anatomski nešto veća nego što bi trebala biti - to je znak ruke koja je radila i ubrala plodove svoga rada. Naposljetku, dominanta i centar cijele slike jest ogromna ljèsa, koja je također napravljena tim rukama i koja "nosi" (jer na njoj se suše) plodove prirode. 
Znak ljèse ne pojavljuje se izravno u poetskom izričaju, međutim u slikama je čest motiv, osobito od šezdesetih do sredine osamdesetih godina. Izgled ljèse je pogodan za mnoga gotovo apstraktna likovna rješenja. Među slikama iz tog razdoblja, znakovno se izdvaja slika Beračica smokava iz 1981. godine. U središte slike postavljen je ženski lik koji iznad glave drži korpu smokava. U pozadini su tri ljèse, koje se svojim oblikom i ritmom sitnih drvenih dijelova stapaju sa ženskim likom. Tako su cijeli gornji dio tijela žene i njezino lice ispresijecani linijama boje koje podsjećaju na uzdužne pritke ljèse. Tim potezom, možemo reći, Puljić poistovjećuje ljèse - pomoćni proizvod teškoga rada koji je nužan za prikupljanje plodova i sušenje, s likom koji ih je stvorio. Ženski lik beračice smokava stapa se sa znakom ljèse i time tvori (postaje) zajednički znak težačkoga života i rada.

Međutim, znak po kojemu je $\mathrm{Pu}$ ljić poznat i koji on sam odabire za označitelja u svojoj poetsko-likovnoj monografiji, jest šipak, odnosno šipci. Mnogi su kritičari naglašavali da je to gotovo njegov zaštitni znak, te da su mu slike s motivom šipaka neka od najboljih ostvarenja i sl. No, nitko nije sagledao simboliku šipka u cjelokupnom kontekstu Puljićeva stvaralaštva. Puljićevi šipci prvenstveno su bili prepoznati tek kao oku ugodni likovni motivi.

Međutim, zahvaljujući pjesmi naziva Šipci taj znak/simbol moguće je interpretirati daleko šire.

"Ne uzgaja ih ljudska ruka,/ nebo o njima ne brine,/ opasale ih zmije oko struka,/ a kamen čuva od vododerine.// Svuda po vrletnim stranama/ uspinju se do vrtoglavice./ Često prezime skoreni na granama/ kao smrznute tice.// Kad se na šipke nebo stušti,/ pod nepca im se uholadže skriju./ Tad poput kurjaka razjape čeljusti/ da se zubatom suncu nasmiju// Trn im je brat, sestra drača./ Kad raspuknu - to se brdo smije./ Dok jesen preko krša drhteći korača,/ krv u šipcima počinje da zrije." 21

Nakon što pročitamo ovu pjesmu $\mathrm{Pu}$ ljićev šipak nije samo lijep dar prirode ili tek ugodan likovni prikaz mrtve prirode - on postaje jedan od najsugestivnijih znakova-simbola hercegovačkoga podneblja uopće (jednako važan kao sunce, kamen, žeđ ili kiša - a možda i važniji jer je rezultanta svih njih). Iz pjesme iščitavamo: šipci rastu između kamena i sunca i uspinju se do vrtoglavih visina. Bez obzira na nepogode neba, oni se smiju zubatom suncu s kojim mogu živjeti, a u jesen kada sve zatihne, u njima krv zrije. Analogijski, znak šipka, kako je donesen u ovoj pjesmi, veoma podsjeća na metaforu bića samoga pjesnika/umjetnika (usporedi: Jablani, Tin Ujević). S druge strane, pak, ako simboliku šipka promatramo u kontekstu likovnih ostvarenja s tim znakom, šipak je znak svojevrsnoga čuda, znak posebnosti ovoga podneblja. Svojim pjesmama i slikama Puljić uvjerljivo opisuje prostor Hercegovine - prostor težak za življenje, zagasit, krutih oblika, strogih, izmučenih i suhih lica žitelja koji se $s$ njime bore. To je prostor u kojem čuče zmije i gušterice pod suncem i kamenjem, to je suh prostor u kojem se teško živi i sve ovisi o po- 
problematiku i pitanja o smislu i istini samoga bitka te ispituje bitak ljudskoga postojanja. ${ }^{25}$ Puljić u svom umjetničkom radu analizira to isto. On čisti svoj poetsko-likovni prostor od svega suvišnoga i postavlja čitav niz znakova kroz koje iščitavamo čovjekovu egzistenciju. Upravo je u tome Puljićev forte. Kada gledamo njegova likovna ostvarenja, vidimo da su ona znakovi zaustavljeni u prostoru, a likovi zamućenih lica i zaustavljenih pokreta koji ih napućuju, njihovi su atributi, koji, također provučeni kroz tonove zagasitosti i sumornosti, govore metaforično o jednome izdvojenom podneblju ali istovremeno su i metafore općenite čovjekove sudbine u našoj razdrtoj suvremenosti. Dakle, likovi, iako stavljeni u ambijentalno označen prostor, ne moraju nužno označavati egzistenciju u označenom prostoru. Oni su lišeni suvišnih atributa i detalja upravo zbog mogućnosti višeznačja.

Vlado Puljić je umjetnik koji je proveo gotovo cijeli svoj život u Hercegovini, i koji je crpio inspiraciju iz Hercegovine i svoga proživljenoga života. $\mathrm{Na}$ ovim prostorima, osim njega, ne postoji umjetnik koji je svoje cijelo stvaralaštvo posvetio Hercegovini viđenoj kroz optiku tradicije i žednog života koji je sudbinska odrednica podneblja. Ta žeđ nije samo fizička žeđ za vodom, nego općenita žeđ za životom i za civilizacijskom otvorenosti ovih prostora.

Za potpuno i pravilno valoriziranje Puljićeva opusa, moraju se zajednički i usporedno promatrati njegova poezi- ja i slikarstvo. Sam umjetnik nam to poručuje koncipiranjem svoje jedine monografije u kojoj je pokraj svake reproducirane slike postavio stihove napisane pjesme. Puljićeve su slike nepravedno smatrane manje uspješnima od pjesama upravo zato što su se promatrale odvojeno od njegovih stihova. Međutim, nakon pročitanih pjesama, one dobivaju sasvim drugu dimenziju, te se upravo tada osjeća ono što je jednom sam Puljić izjavio - da su one samo dio njegovih pjesama.

Promatrati njegove slike bez pročitanih pjesama, i obratno - potpuna je pogrješka. Jer Puljić svoje ideje uvijek iznosi dihotomnim diskursom - kroz dvije vrste pisanja - riječju i slikom. Zato bismo njima uvijek morali pristupiti kao neodvojivom tkivu, tkivu koje jedno drugo nadopunjava čineći jedinstveni zajednički znak.

Cilj ovoga rada jest pridonijeti raščlambi Puljićeva stvaralaštva kroz šire sagledavanje i povezivanje njegove slike i riječi, upravo onako kako se i sam umjetnik nastojao izraziti. To se ne bi smjelo zanemariti, osobito ako o Puljićevu stvaralaštvu piše povjesničar/ka umjetnosti, ali i bilo koji drugi poslenik ćiji je zadatak uputiti gledatelja/čitatelja na jedinstvo njegovih znakova i mogućnosti njihova iščitavanja.

Također, rad bi mogao poslužiti kao poticaj za daljnje istraživanje ne samo Puljićeva stvaralaštva, nego i stvaralaštva drugih umjetnika čiji rad priziva semiotičko sagledavanje $i($ li) interdisciplinarni pristup obradi riječi i slike.

25 Usp. Martin Heidegger, Bitak i vrijeme, Naprijed, Zagreb, 1985. 


\section{New approach to Vlado Puljićs painting and poetry}

\section{Summary}

Through selected examples of Vlado Puljic's poetry and painting, the paper will offer a new interdisciplinary approach to his art based on the most appropriate theoretical fundament of semiotics. The paper consists of two main parts. The first one is a theoretical view of differences between word and painting whereas the second part gives concrete examples which depict signs as basics of his creativity. Considering Puljic's art, the meaning of his poetic and painting signs will be explained in the examples which a reader/viewer can understand only by knowing both poetry and painting. As an interdisciplinary approach, it can be used for interpretation of other similar artistic forms.

Keywords: Vlado Puljić, picture and word, semiotics, sign, Herzegovina. 